\title{
Facile Construction of Copper Mesh Surface from Superhydrophilic to Superhydrophobic for Various Oil-Water Separations
}

\author{
Xudong Zhang, ${ }^{1, *}$ Yamin Pan, ${ }^{1,2, t}$ Junyang Zhao, ${ }^{1}$ Xiaoqiong Hao, ${ }^{3}$ Yaming Wang, ${ }^{1, *}$ Dirk W Schubert, ${ }^{2}$ Chuntai Liu, ${ }^{1}$ Changyu Shen ${ }^{1}$ and \\ Xianhu Liu ${ }^{1,2^{*}}$
}

Specially wettability materials offer a new pathway for effective oil-water separation. However, these materials with desired wettability, simple process and low cost as well as high efficiency separation are still urgently needed. Herein, facile strategies, acid etching and PDMS coating, were reported for the construction of copper mesh surfaces with special wettability from superhydrophilic to superhydrophobic. In the first acid etching, copper mesh surface exhibits a superhydrophilic and underwater superoleophobic properties, and the etched copper mesh with high separation efficiencies (92\%) was obtained. After PDMS coating, a low adhesion superoleophilic and superhydrophobic copper mesh shows high water contact angle of $153^{\circ}$, high flux $\left(\sim 31000 \mathrm{~L}^{*} \mathrm{~m}^{-2 *} \mathrm{~h}^{-1}\right)$, excellent anti-icing and self-cleaning performances. Additionally, after UVB, mechanical wear, hot water and acid/alkaline solution treating, the coated mesh still showed excellent water-repellency performance. Moreover, the coated mesh by connecting with a vacuum pump was used for continuous oil-water separation. This work provides not only a simple and efficient method to fabricate controllable wettability copper mesh with oil-recovery ability but also a new opportunity for potential applications in continuous oil-water separation.

Keywords: Low adhesion; Oil-water separation; Superhydrophobic; Superoleophilic

Received 24 December 2018, Accepted 11 March 2019

DOI: $10.30919 / \mathrm{es} 8 \mathrm{~d} 505$

\section{Introduction}

In the oil extraction process and industrial production, a lot of oil-water mixture is produced. If improperly handled, it may cause waste of resources, endanger human health and cause pollution to environment. ${ }^{1,2}$ People solve this problem by using oil-water separation materials. These materials require different wettability for water and oil. Superhydrophobic materials have attracted research interests of many researchers with a broad application prospects in anti-icing, selfcleaning, oil-water separation and so on. ${ }^{3-7}$ Specially wettability materials are mainly related to their surface roughness and surface free energy. ${ }^{8}$

Superhydrophobic mesh surfaces with the micro/nano-structures have been reported by chemical vapor deposition, ${ }^{4}$ spray deposition, ${ }^{9}$ hydrothermal method, ${ }^{10}$ foaming, ${ }^{11-15}$ and so on, ${ }^{16-20}$ However, above methods usually need complex equipment and high cost. The chemical etching method can get a micro/nano-structure on the material surfaces with low cost, low energy consumption, no precision instruments required. ${ }^{21,22}$ Commercially available raw material copper mesh has low price and can be widely selected. Due to its own uniquely porous

${ }^{1}$ College of Materials Science and Engineering; National Engineering Research Center for Advanced Polymer Processing Technology, Zhengzhou University, Zhengzhou 450001, China

${ }^{2}$ Institute of Polymer Materials, Friedrich-Alexander University Erlangen-Nuremberg, Martensstr. 7, 91058 Erlangen, Germany

${ }^{3}$ School of Science, Xi'an Jiaotong University, 28 Xianningxi, Xi'an, Shaanxi 710049, China

*E-mail: wangyaming@zzu.edu.cn; xianhu.liu@zzu.edu.cn structure, it provided natural channels for the oil to be collected during the oil-water separation process. The filtration method is not affected by the amount of adsorption, easy to use, and no further separation of oil and separation materials. As is well known, micro/nano-structures and low surface energy substance simultaneously exist on the surface of material, the surface of the material exhibits superhydrophobic. PDMS (Polydimethylsiloxane) was commonly used for low surface energy modification, because of the contains low surface energy elements and group such as $\mathrm{Si}, \mathrm{C}$ and methyl etc. ${ }^{23}$ In this work PDMS was used to low surface energy modification of the substance.

In this work, a superhydrophobic and superoleophilic copper mesh with micro/nano- structures was reported via a rapid, low cost and highly effective solution process and low surface energy modification though coating with PDMS. The prepared copper mesh used for oilwater separation possessing high flux was fabricated with two-step micro/nano-structure formation and low surface energy modification. The key point in this research is to provide a simple method to create a micro/nano-structure which is through a simple displacement reaction. The prepared sample has a waterproof impact property while can be used for continuous oil-water separation.

\section{Experimental}

\subsection{Materials}

Copper meshes with pore diameters of $60 \mu \mathrm{m}$ were bought from Shenzhen Ante Metal Wire Mesh Product Factory. Silver nitrate $\left(\mathrm{AgNO}_{3}\right)$ and PDMS with its curing agent were purchased at Sinopharm Group Chemical Reagent Co., LTD and Dow Corning, respectively. All other chemicals including anhydrous ethanol, hexane and xylene were bought from Tianjin Fuyu Fine Chemical Co., Ltd. All chemicals were 
used as received without further purification.

\subsection{Preparation of specially wettable mesh}

Copper meshes (200 mesh size) were first ultrasonically cleaned for 10 min in the solution of deionized water, alcohol, acetone and concentration of $20 \%$ sulfuric acid in order to remove the oxide and any organic layers. After drying, they were immersed in the solution of $0.01 \mathrm{M} \mathrm{AgNO}_{3}$ and $100 \mathrm{~mL}$ ethanol at room temperature for $30 \mathrm{~s}$. Then the meshes were rinsed with deionized water and dried in the blast oven at $80{ }^{\circ} \mathrm{C}$ for $20 \mathrm{~min}(\mathrm{Cu}-\mathrm{Ag})$. For the coated meshes (Cu-Ag-P), $\mathrm{Cu}-\mathrm{Ag}$ was immersed into a solution of $3 \mathrm{~g}$ PDMS and $100 \mathrm{~mL}$ xylene at room temperature for $10 \mathrm{~s}$ and dried at $80{ }^{\circ} \mathrm{C}$ for $120 \mathrm{~min}$ (Fig. S1).

\subsection{Characterization}

The surface structure of the rough surface was observed by a fieldemission scanning electron microscope (Hitachi, S-4800, Japan, 20kV). Chemical composition data of films on copper mesh was characterized by EDS. Contact angle meter (SL200KS, KINO, USA) with a liquid droplet of $2 \mu \mathrm{L}$ was used for water contact angle (WCA) and oil contact angle (OCA) test. Fourier Transform Infrared spectrophotometer (FT-IR, Nicolet 6700, USA) were used to examine the chemical composition. Droplet impact test was used a water droplet of $6 \mu \mathrm{L}$ at a height of $6 \mathrm{~cm}$, and a high-speed camera (Qianyan Lang 2F04, Junda Hi-Tech Co., Ltd.) captured the drop process at a frequency of 1000 frames.

\subsection{Oil-water separation}

Vacuum pump oil, silicone oil soybean oil, hexane and dichloromethane were colored with Sudan III. Cu-Ag-P was fixed on the filtration devices for the mixtures of oil and water $(50 \% \mathrm{v} / \mathrm{v})$ separation. The separation efficiency was calculated by $\mathrm{G}=\left(\mathrm{m}_{1} / \mathrm{m}_{0}\right) \times 100 \%$, where $\mathrm{m}_{0}$ and $\mathrm{m}_{1}$ were the masses of the water before and after separation, respectively.

\section{Results and discussion}

The raw copper mesh knitted by wires has an average pore size of about $60 \mu \mathrm{m}$ (Fig. 1a). From the SEM of copper mesh, we can find that in macroscopically its relatively smooth but further enlarged there are small gully structure which provides a larger area to reaction with $\mathrm{AgNO}_{3}$. After etching, the silver particles attach the surface of wires evenly, and the surface of etched copper mesh ( $\mathrm{Cu}-\mathrm{Ag})$ becomes roughness (Fig. 1b). As shown in the picture there are petal-like micro/nano-structure on the surface of copper wires which can significantly change the wetting properties of the material surface. The surface elements of the copper mesh were analyzed by EDS (Fig. 1c). From the EDS spectra, the $\mathrm{Cu}$, and $\mathrm{Zn}$ elements were found in the surface. Ag elements was found on the $\mathrm{Cu}-\mathrm{Ag}$ surface (Fig. 1d), which certificate that the micro/nano-structures were composition by $\mathrm{Ag}$, and the surface was modified by the Ag.

$\mathrm{Cu}-\mathrm{Ag}$ displayed Superhydrophilic/Superlipophilic in air but

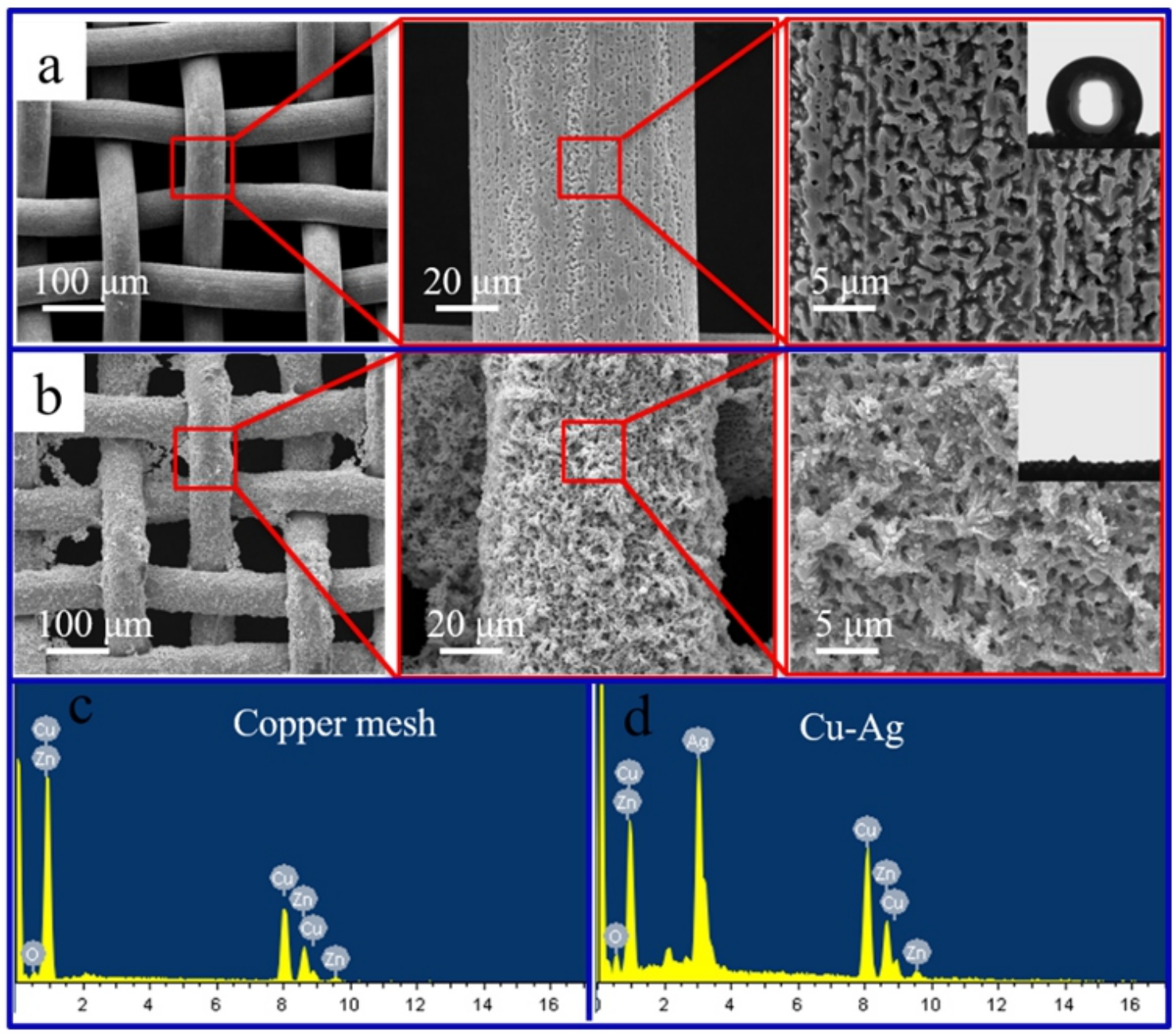

Fig. 1 SEM of the (a) copper mesh, (b) etched copper mesh (Cu-Ag); EDS analysis of the surface element of the (c) copper mesh and (d) Cu-Ag. 
underwater oleophobicity and under cyclohexane hydrophobic. This is attributed to the combination effect of the changed surface composition and the enhanced surface roughness. The (water or oil) droplet deposited on the $\mathrm{Cu}-\mathrm{Ag}$ surface spread rapidly, indicating an OCA and WCA of $0^{\circ}$ (Fig. 2a and c). When a trichloromethane or water was placed on the $\mathrm{Cu}-\mathrm{Ag}$ in water (Fig. 2b) or cyclohexane (Fig. 2d), it still maintained sphere, showing excellent underwater oleophobicity or under cyclohexane hydrophobic with OCA of $132^{\circ}$ and WCA $135^{\circ}$. Comparison with the WCA of the original copper mesh $120^{\circ}$, the $\mathrm{Cu}-$ Ag surface with the deposition of silver micro-nano structures form on the surface and the chemical composition of the surface change has changed. According to the Wenzel model with the increasing of the microstructure on the surface of a hydrophilic material while increases the hydrophilicity of the material. ${ }^{24,25}$

Due to the superhydrophilicity and underwater oleophobicity of the $\mathrm{Cu}-\mathrm{Ag}$ (pre-wetted by water), water permeated through it while pump oil was blocked, and no pump oil was visible in the separated water (Fig. 2e). Fig. S2 shows the oil-water separation mechanism of the $\mathrm{Cu}-\mathrm{Ag}$. The separation efficiencies of $\mathrm{Cu}-\mathrm{Ag}$ are all above $92 \%$ during 10 cycles (Fig. 2f), indicating quite stable and durable superwettability of the etched copper meshes. ${ }^{26}$

After coated PDMS, the chemical composition (Fig. S3) and surface element (Fig. S4) results shows that low surface energy materials have been successfully combined. As shown in Fig. 3a, the water can retain a spherical state on the $\mathrm{Cu}-\mathrm{Ag}-\mathrm{P}$ surface. However, the oil droplets spread rapidly and exhibited superlipophilic properties (Fig.

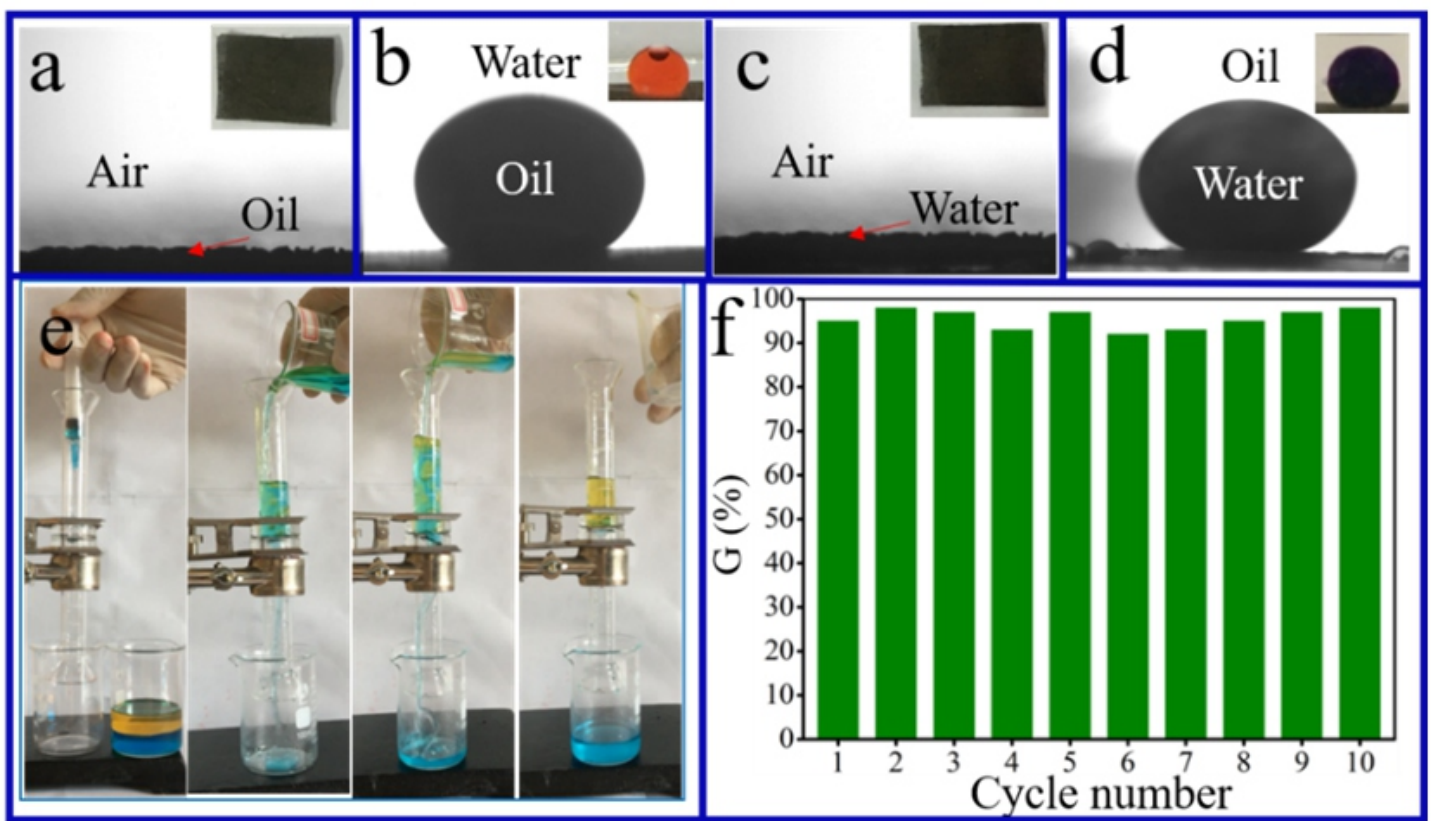

Fig. 2 (a) OCA in air and (b) underwater of $\mathrm{Cu}-\mathrm{Ag}$; (c) WCA in air and (d) under cyclohexane of Cu-Ag; (e) The separation experiment of pump oilwater mixture by the $\mathrm{Cu}-\mathrm{Ag}$; (f) Oil-water separation efficiency in 10 cycles.

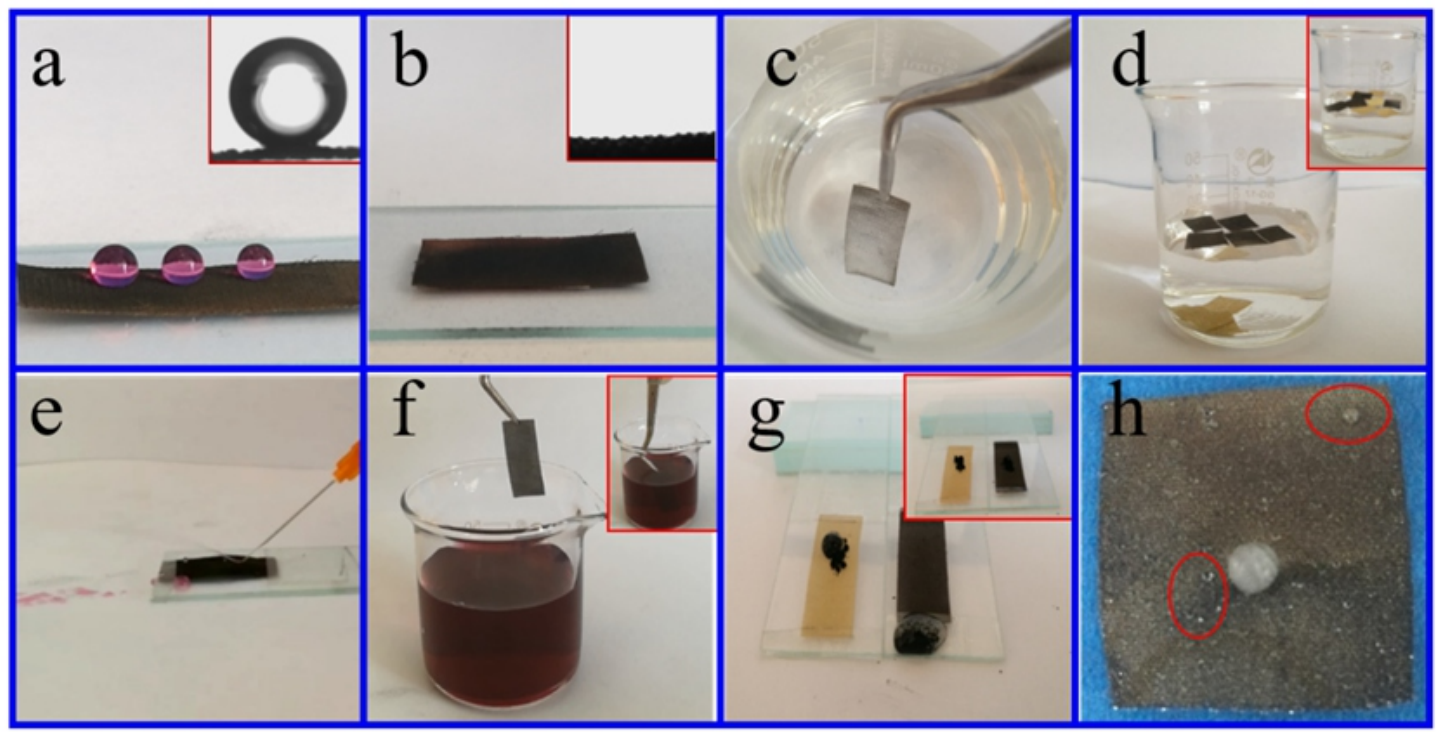

Fig. 3 (a) WCA and (b) OCA on the surface of Cu-Ag-P; (c) immersion the Cu-Ag-P in water; (d) photo of Cu-Ag-P and copper mesh in the water after shake; (e) water flow impact on $\mathrm{Cu}-\mathrm{Ag}-\mathrm{P}$ surface; (f) immersion the $\mathrm{Cu}-\mathrm{Ag}-\mathrm{P}$ in water (dyed by $\mathrm{KMnO}_{4}$ ) by force; ( $\mathrm{g}$ ) self-cleaning of the $\mathrm{Cu}-\mathrm{Ag}-\mathrm{P}$ though the removal of CNT from the surface using water droplets; (h) Photographs of the water drops frozen on the surface of Cu-Ag-P. 
3b). After the Cu-Ag-P immersed into water, a bright plastron layer can be observed (Fig. 3c) due to the total reflectance of light at air layer trapped on the surface. This air layer can even make the copper mesh and the $\mathrm{Cu}-\mathrm{Ag}-\mathrm{P}$ float on the calm water. However, when shake the beaker, copper mesh can sink easily while the $\mathrm{Cu}-\mathrm{Ag}-\mathrm{P}$ is still floating on the water (Fig. 3d).

The lower adhesion properties of the samples are important for self-cleaning and anti-fouling. Fig. 3e shows the impact of water flow on the $\mathrm{Cu}-\mathrm{Ag}-\mathrm{P}$ surface. The water flow completely reflected, and no water droplets remain in the impact position. In addition, after the $\mathrm{Cu}$ Ag-P was completely immersed in water and removed from the water (Fig. 3f) for 3 times, there was no water droplets on the $\mathrm{Cu}-\mathrm{Ag}-\mathrm{P}$ surface. Low adhesion of $\mathrm{Cu}-\mathrm{Ag}-\mathrm{P}$ to water. To check the self-cleaning properties, self-cleaning tests were carried out. The water droplets on the copper mesh surface appearing as a hemisphere (Fig. 3g), and the carbon nanotubes (CNTs, as a conventional pollutant) were stayed in place. However, when the water dripped on the $\mathrm{Cu}-\mathrm{Ag}-\mathrm{P}$ surface, it rolled away to remove CNTs, leading a clean surface. Above results show that the $\mathrm{Cu}-\mathrm{Ag}-\mathrm{P}$ has good self-cleaning property.

The actual anti-icing performance of the $\mathrm{Cu}-\mathrm{Ag}-\mathrm{P}$ was studied via static experiments in low temperature environment $\left(-4^{\circ} \mathrm{C}\right)$. In the static anti-icing experiment, a $10 \mu \mathrm{L}$ water drop was put on the $\mathrm{Cu}-\mathrm{Ag}$ P. The freezing process was observed and recorded by a camera. (Fig. $3 \mathrm{~h})$. The water drop can retain a spherical state on the $\mathrm{Cu}-\mathrm{Ag}-\mathrm{P}$ surface, after $12 \mathrm{~h}$ the water droplets are completely frozen. This frozen water droplet still remains spherical. At the same time, we can also find other small spherical droplets that are frozen around it. This phenomenon can prove the low adhesion of the material surface.

To prove this phenomenon, Owens formula were utilized to calculate the surface energy. ${ }^{27}$ Water and glycol were chosen as tested liquids. Surface tension of the tested liquids was shown in Table1.

$$
1+\cos \theta_{0}=2 \sqrt{\gamma_{s g}^{d}}\left(\sqrt{\gamma_{l g}^{d}} / \sqrt{\gamma_{l g}}\right)+2 \sqrt{\gamma_{s g}^{p}}\left(\sqrt{\gamma_{l g}^{p}} / \sqrt{\gamma_{l g}}\right)
$$

$\gamma_{l g}^{d}$ and $\gamma_{l g}^{p}$ are the dispersion component and polar component of liquid surface tension, respectively. And $\gamma_{s g}^{d}$ and $\gamma_{s g}^{p}$ are the dispersion component and polar component of solid surface energy, respectively. $\gamma_{l g}$ is the liquid surface tension. The calculated results were shown in Table 2. From the results of the surface energy, the superhydrophobic copper mesh displayed energy decreased in comparison with the rough mesh and the blank mesh. This result was consistent with the contact angles of the modified samples.

The impingement of water droplets on surface is inevitably during practical applications. To prove the anti-water impact performance, water droplets of $6 \mu \mathrm{L}$ with a velocity of $1.09 \mathrm{~m} / \mathrm{s}$ and fall height of $6 \mathrm{~cm}$ were used for water droplet impact experiment. The water hammer pressure $\left(P_{W H}\right)$ can be approximated by Eq. (2)

$$
P_{W H} \approx 0.2 \rho C V
$$

where $\rho$ is the water density $\left(1000 \mathrm{~kg} / \mathrm{m}^{3}\right), C$ is the sound velocity in water $(\sim 1497 \mathrm{~m} / \mathrm{s})$, and $V$ is the velocity of the water droplet. ${ }^{28}$ The calculated $P_{W H}$ is $0.326 \mathrm{MPa}$. The water droplet can bounce off the $\mathrm{Cu}$ Ag-P surface 5 times (Fig. 4a), showing an extended bouncing process for longer periods of time $(240 \mathrm{~ms})$. Obviously, after the water droplet impacted the $\mathrm{Cu}-\mathrm{Ag}$-P surface, the water droplets completely projected off the surface. More importantly, no evidence of water droplet residue was observed during the whole impingement process. This is attributed to the relatively lower vertical adhesive force between the water droplet and the Cu-Ag-P surface. Compared to the copper mesh surface, a complete wetting state after the impingement was found. Above results suggest that the $\mathrm{Cu}-\mathrm{Ag}-\mathrm{P}$ surface has an excellent antiwetting performance.

To further understand the hydrophobic state's difference between the $\mathrm{Cu}-\mathrm{Ag}-\mathrm{P}$ and copper mesh, the water droplet evaporation experiment was performed. The water drops height $(H)$ on the copper mesh and Cu-Ag-P surfaces were analyzed. The white lines in Fig. $4 \mathrm{~b}$ represent the liquid-solid contact diameters of the droplets. The diameter of the liquid-solid contact surface of $\mathrm{Cu}-\mathrm{Ag}-\mathrm{P}$ with a low adhesion gradually decreases with the evaporation of water droplets. But, the surface-solid contact diameter of the copper mesh remained almost unchanged for $18 \mathrm{~min}$. During the evaporation process, $H$ gradually decreases, but it decreases faster on the copper mesh due to its highly-adhesive nature. In addition, the WCA of $\mathrm{Cu}-\mathrm{Ag}$-P is almost constant for the first $13 \mathrm{~min}$ and then decreases. However, the WCA of the copper mesh gradually decreases. Accordingly, the evaporation of water droplets on the copper mesh surface obeys the law of constant liquid-solid contact diameter, while the $\mathrm{Cu}-\mathrm{Ag}-\mathrm{P}$ surface obeys the constant contact angle rules. ${ }^{29,30}$ This difference is mainly caused by different movements of the three-phase contact lines on the two

Table 1 Surface tension of tested liquids.

\begin{tabular}{cccc}
\hline Tested liquid & $\begin{array}{c}\text { Surface tension } \\
(\mathrm{mN} / \mathrm{m})\end{array}$ & $\begin{array}{c}\text { Dispersion component } \\
(\mathrm{mN} / \mathrm{m})\end{array}$ & $\begin{array}{c}\text { Polar component } \\
(\mathrm{mN} / \mathrm{m})\end{array}$ \\
\hline Water & 72.8 & 21.8 & 51.0 \\
Glycol & 48.3 & 29 & 19.3 \\
\hline
\end{tabular}

\begin{tabular}{|c|c|c|c|c|c|}
\hline Sample & $\begin{array}{l}\text { WCA } \\
\left(^{\circ}\right)\end{array}$ & $\begin{array}{c}\text { Glycol CA } \\
\left(^{\circ}\right)\end{array}$ & $\begin{array}{c}\gamma_{s g}^{d} \\
(\mathrm{mN} / \mathrm{m})\end{array}$ & $\begin{array}{c}\gamma_{s g}^{p} \\
(\mathrm{mN} / \mathrm{m})\end{array}$ & $\begin{array}{c}\text { Surface energy } \\
(\mathrm{mN} / \mathrm{m})\end{array}$ \\
\hline Copper mesh & 127 & 100 & 19 & 0.7 & 19.7 \\
\hline $\mathrm{Cu}-\mathrm{Ag}-\mathrm{P}$ & 151 & 130 & 5 & 0.7 & 5.7 \\
\hline
\end{tabular}

Table 2 Results of calculated surface energy of the sample. 
surfaces. During the evaporation of water droplets, the water droplets on the $\mathrm{Cu}-\mathrm{Ag}-\mathrm{P}$ surface have low-adhesion, and therefore the liquidsolid contact line can be easily changed. On the contrary, the copper mesh has a large adhesion to water droplets. The solid contact line is difficult to be changed, so the liquid-solid contact diameter is almost constant, and the drop height is reduced more quickly, so the contact angle is reduced more significantly.
Recently, various superhydrophobic meshes via coated the lower surface energy materials have been reported. ${ }^{34}$ However, the low surface energy coating is easy to be damaged during the oil-water separation, which has potential to bring about the loses of hydrophobic nature. Therefore, the final performance of the meshes determines whether it can realize industrialization. Therefore, it is very necessary to study the service behavior of materials in harsh environments. Fig. 5a shows the
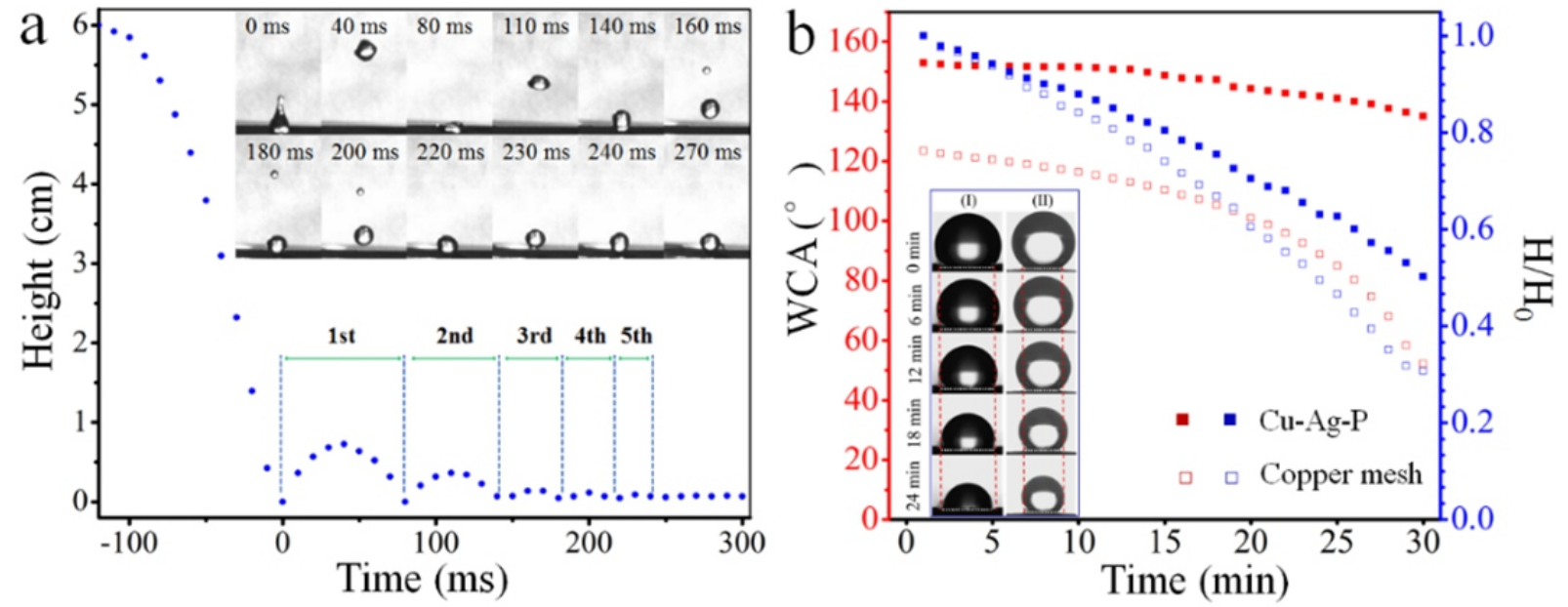

Fig. 4 (a) Rebound height of water droplets vs. time. Insets show the time evolution of droplet-impact dynamics upon the Cu-Ag-P surface; (b) WCA and height ( $H$ is the height of the drop, $H_{0}$ is the initial height before water droplets evaporate) during the evaporation of water droplets. Insets are the image of droplet evaporation on the (I) copper mesh and (II) Cu-Ag-P surface.
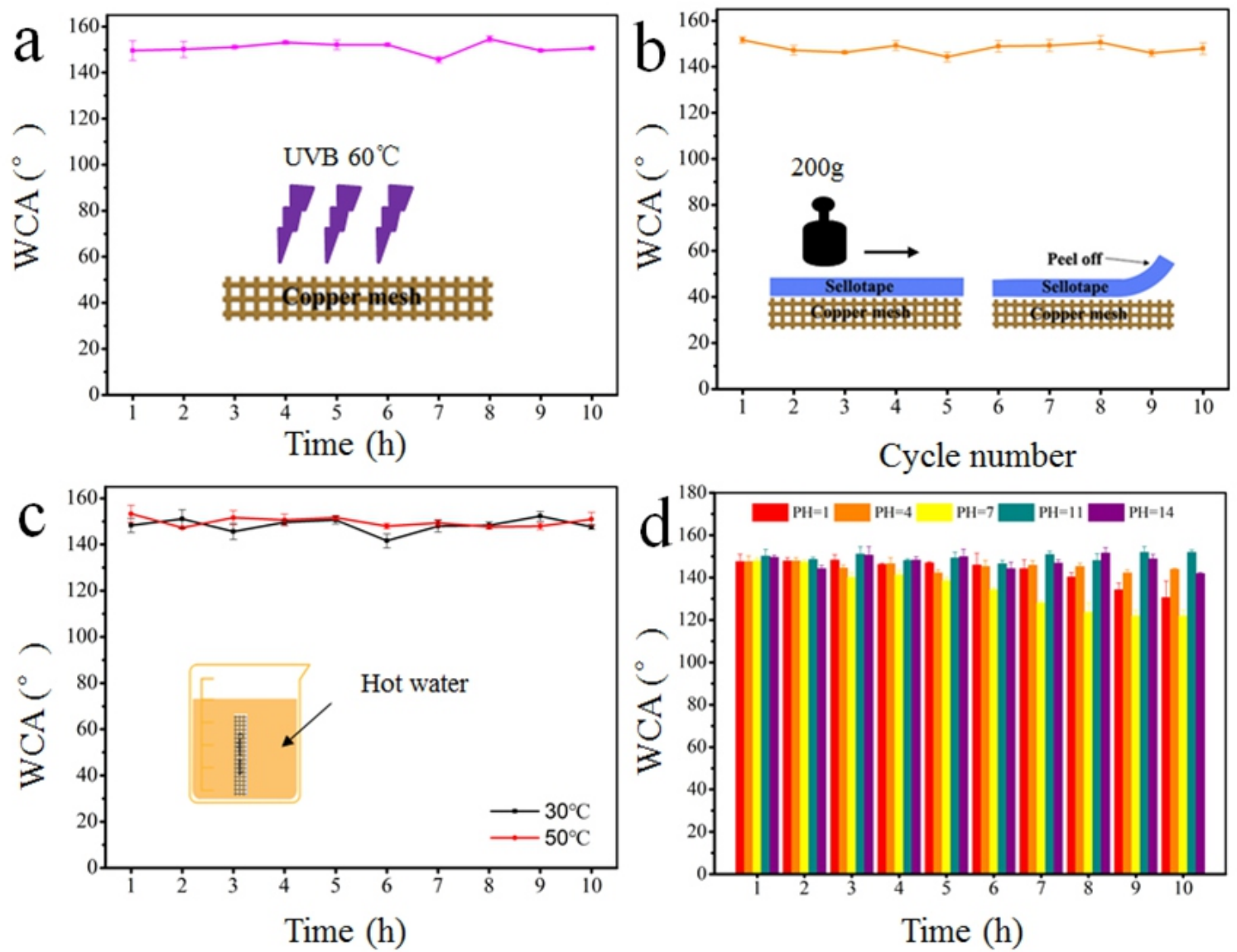

Fig. 5 (a) Variation of WCAs on the Cu-Ag-P treats by UVB (ultraviolet radiation b) as a function of time; (b) dependence of WCAs on the peeling times of the $\mathrm{Cu}-\mathrm{Ag}-\mathrm{P}$; (c) variation of WCAs on the Cu-Ag-P treats by hot water as a function of time (insets show the schematic diagram of the test); (d) WCA change with time in different $\mathrm{PH}$ value in ten hours. 
WCAs on the Cu-Ag-P treats by UVB as function of time. Clearly, the $\mathrm{Cu}-\mathrm{Ag}-\mathrm{P}$ has the stable superhydrophobility under UVB treat. Fig. 5b shows the specific method of sellotape peel off the $\mathrm{Cu}-\mathrm{Ag}-\mathrm{P}$ surface. The WCA of $\mathrm{Cu}-\mathrm{Ag}-\mathrm{P}$ is still more than $144^{\circ}$ after 10 times peeling, showing the optimal water repellency and the outstanding mechanical stability. Moreover, it is inevitable to encounter hot water and harsh environment in practical application. Fig. 5c shows that WCA is more than $140^{\circ}$ in $30{ }^{\circ} \mathrm{C}$ and $50{ }^{\circ} \mathrm{C}$ water for 10 hours. Fig. $5 \mathrm{~d}$ shows the WCAs on the $\mathrm{Cu}-\mathrm{Ag}-\mathrm{P}$ as a function of time immersion in different $\mathrm{pH}$ values. The stable hydrophobicity to water under different $\mathrm{pH}$ values was found. However, after 5 hours, the $\mathrm{Cu}-\mathrm{Ag}-\mathrm{P}$ in the strong corrosion solution, such as $\mathrm{pH}=7$ ( 5 wt. $\% \mathrm{NaCl})$, has WCA drops significantly. Nevertheless, the above results indicate that the $\mathrm{Cu}-\mathrm{Ag}-\mathrm{P}$ can withstand the harsh environment test.

Because the $\mathrm{Cu}-\mathrm{Ag}-\mathrm{P}$ has the properties of superhydrophobic and superoleophilic, it is selective to adsorb oil droplets when the sample is placed in an oil-water mixture. Therefore, $\mathrm{Cu}-\mathrm{Ag}-\mathrm{P}$ is more applicable for oil or organic solvents spill clean. When the cyclohexane was

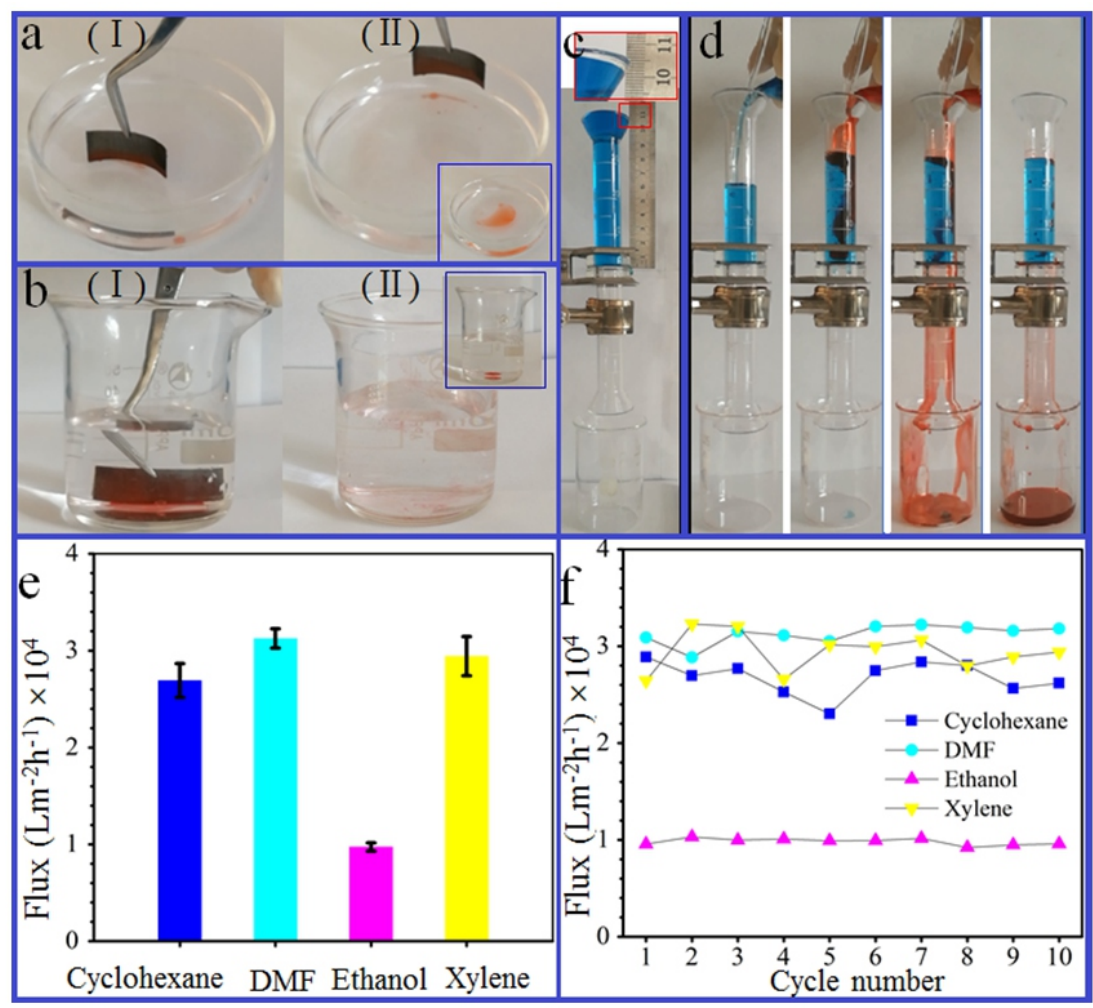

Fig. 6 On-water (a) and under-water (b) adsorption of organic solvents; (c) The water intrusion of Cu-Ag-P (water is dyed with methyl blue); (d) serious of images of trichloromethane and water mixture use of the mesh for separation; (e) result of different organic solvents fluxes; (f) changes of organic solvent fluxes in ten cycles.

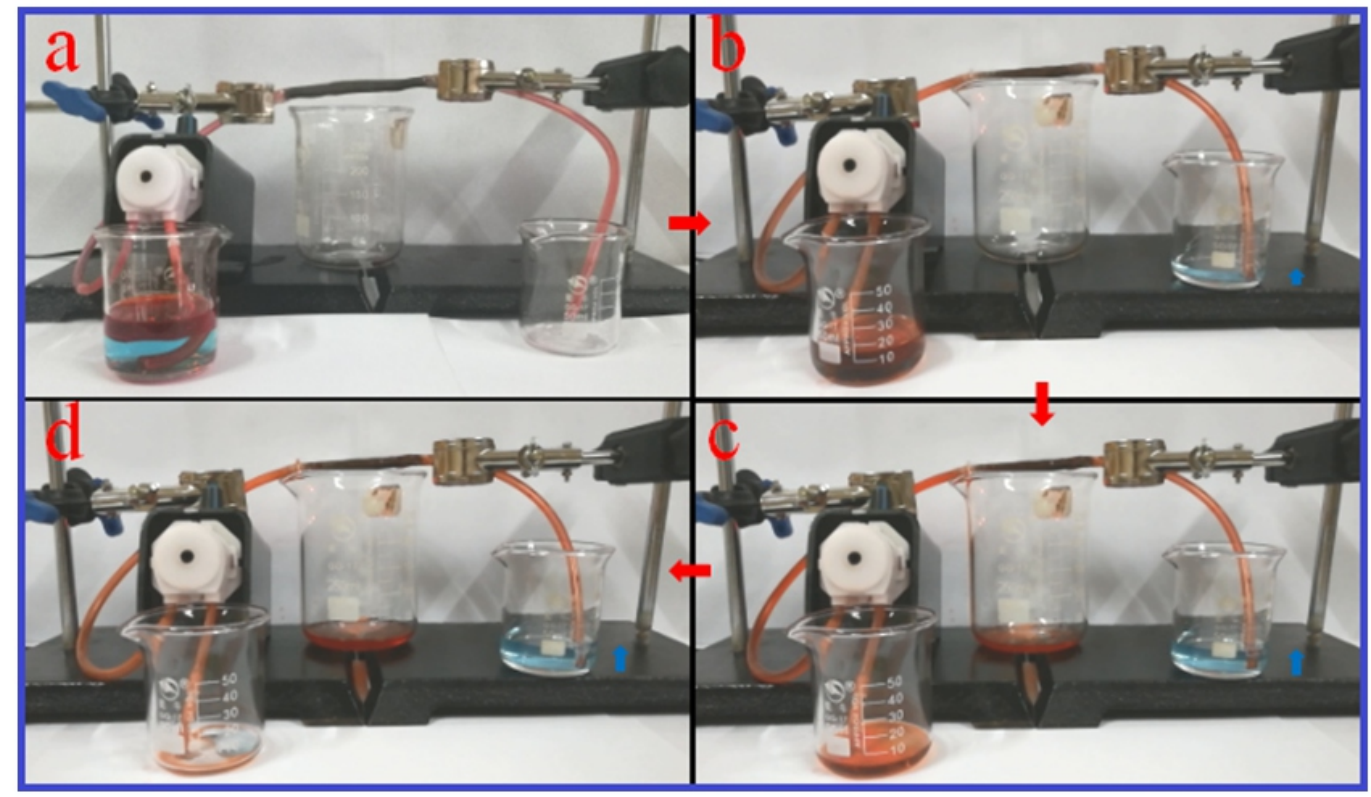

Fig. 7 Photographs of the oil-water separation apparatus with cyclohexane-water mixture. 
dropped on the water, it would float on the surface (Fig. 6a). A small piece of $\mathrm{Cu}-\mathrm{Ag}-\mathrm{P}$ was put on the water and the cyclohexane was gradually adsorbed. When the sample was removed from the water, it would like the organic solvents away. Meantime, for organic solvents with a density greater than water, it can also be used to absorb organic solvents underwater (Fig. 6b). The maximum height of water $\left(h_{\max }\right)$ that the $\mathrm{Cu}-\mathrm{Ag}-\mathrm{P}$ can support reflects the intrusion pressure. Therefore, the intrusion pressure can be calculated by Eq. (3)

$$
p=\rho g h_{\max }
$$

where $g$ is the gravitational acceleration. From Fig. $6 \mathrm{c}, h_{\max }$ is $10.1 \mathrm{~cm}$, and $p$ is about $1.01 \mathrm{kPa}$. That is, the water cannot permeate the mesh under $1.01 \mathrm{kPa}$.

In our study, the Cu-Ag-P was used as a separation membrane, which allowed the easy and free passage of a liquid. As shown in Fig. $6 \mathrm{~d}$, the $\mathrm{Cu}-\mathrm{Ag}-\mathrm{P}$ was fixed between two glass tubes and a dichloromethane/water mixture put into the upper glass tube. Because of the superoleophilicity and superhydrophobicity of the $\mathrm{Cu}-\mathrm{Ag}-\mathrm{P}$, the trichloroethanes quickly passed though the $\mathrm{Cu}-\mathrm{Ag}-\mathrm{P}$, but water still was retained on top of the $\mathrm{Cu}-\mathrm{Ag}-\mathrm{P}$ in the upper glass tube. Therefore, we conclude that this simple gravity action can be used to separate the oil and water through the $\mathrm{Cu}-\mathrm{Ag}-\mathrm{P}$.

The flux of the $\mathrm{Cu}-\mathrm{Ag}-\mathrm{P}$ was calculated by Eq. (4)

$$
F l u x=V /(S \times t)
$$

where $V$ is the volume of permeating liquid, $S$ is the effective area of the film, and $t$ is the permeating time..$^{35-39}$ As shown in Fig. 6e, the $\mathrm{Cu}-$ Ag-P shown a high oil flux owing to the superoleophilicity with low viscosities and the flux reached $3.1 \times 10^{4} \mathrm{~L}^{*} \mathrm{~m}^{-2} * \mathrm{~h}^{-1}$ for DMF. The flux mainly depends on the oil viscosity. However, no significant change of flux in 10 cycles was observed (Fig. 6f), indicating the good stability of the $\mathrm{Cu}-\mathrm{Ag}-\mathrm{P}$. Therefore, the $\mathrm{Cu}-\mathrm{Ag}-\mathrm{P}$ can be used to separate oil and water effectively.

Based on the strong water repellency and high flux oil of the coated mesh, an oil-water separation device is used to test the oil-water separation (Fig. 7). The core part of the device is the separating mesh rolled by the $\mathrm{Cu}-\mathrm{Ag}-\mathrm{P}$. The oil can be rapidly permeated the $\mathrm{Cu}-\mathrm{Ag}-\mathrm{P}$ entered fall into the oil collector while the water goes forward by the continuous drive and finally entered fall into the water collector. Thus, oil-water can be separated thoroughly and efficiently.

\section{Conclusion}

The copper meshes with superhydrophilic/superlipophilic characteristic were prepared by Ag particles deposition which can be used for oilwater separation. After coat PDMS, a superhydrophilic copper mesh was obtained. Under UVB, mechanical wear, hot water, and acid, alkaline solution, the superhydrophobic mesh still shows excellent water-repellency performance. Due to the opposite wettability, the superhydrophobic mesh can remove oil from the oil-water mixture under only a gravity-drive force. The superhydrophobic copper mesh has a high flux $\left(31000 \mathrm{~L}^{*} \mathrm{~m}^{-2} * \mathrm{~h}^{-1}\right)$ for diverse organic solvents.

\section{Acknowledgements}

We express our great thanks to the National Natural Science Foundation of China $(51803190,11432003,11572290)$ and National Key Research and Development Program of China (2016YFB0101602) for financial support.

\section{Reference}

1. Z. Xue, S. Wang, L. Lin, L. Chen, M. Liu, L. Feng and L. Jiang, $A d v$. Mater., 2011, 23, 4270-4273.

2. Z. Xue, Y. Cao, N. Liu, L. Feng and L. Jiang, J. Mater. Chem. A, 2014, 2, 2445-2460.

3. A. Rather and U. Manna, J. Mater. Chem. A, 2017, 5, 15208-15216.

4. X. Deng, L. Mammen, H. Butt and D. Vollmer, Science, 2012, 335, 67-70.

5. V. Singh, C. Huang, Y. Sheng and H. Tsao, J. Mater. Chem. A, 2018, 6, 2279-2288.

6. A. Rather, N. Jana, P. Hazarika and U. Manna, J. Mater. Chem. A, 2017, 5, 23339-23348.

7. X. Wang, Y. Pan, C. Shen. C. Liu and X. Liu, Macromol. Rapid Commun., 2018, 39, 1800635.

8. L. Feng, S. Li, Y. Li, H. Li, L. Zhang, J. Zhai, Y. Song, B. Liu, L. Jiang and D. Zhu, Adv. Mater., 2002, 14, 1857-1860.

9. Y. Li, B. Li, X. Zhao, N. Tian and J. Zhang, ACS Appl. Mater. Interfaces, 2018, 10, 39391-39399.

10. S. Wang, C. Wang, C. Liu, M. Zhang, H. Ma and J. Li, Colloids Surf. A, 2012, 403, 29-34.

11. L. Li, W. Li, L. Geng, B. Chen, H. Mi, K. Hong, X. Peng and T. Kuang, Chem. Eng. J., 2018, 348, 546-556.

12. L. Geng, L. Li, H. Mi, B. Chen, P. Sharma, H. Ma, B. S. Hsiao, X. Peng and T. Kuang, ACS Appl. Mater. Interfaces, 2017, 9, 21071-21076.

13. T. Kuang, F. Chen, L. Chang, Y. Zhao, D. Fu, X. Gong and X. Peng, Chem. Eng. J., 2017, 307, 1017-1025.

14. T. Kuang, L. Chang, F. Chen, Y. Sheng, D. Fu and X. Peng, Carbon, 2016, 105, 305-313.

15. H. Zhang, S. Lyu, X. Zhou, H. Gu, C. Ma, C. Wang, T. Ding, Q. Shao, H. Liu and Z. Guo, J. Colloid. Inter. Sci., 2019, 536, 245-251.

16. Q. Liu, D. Chen and Z. Kang, ACS Appl. Mater. Interfaces, 2015, 7, 1859-1867.

17. H. Gu, H. Zhang, J. Lin, Q. Shao, D. P. Young, L. Sun, T. D. Shen and Z. Guo, Polymer, 2018, 143, 324-330.

18. X. Xu, H. Zhang, C. Ma, H. Gu, H. Lou, S. Lyu, C. Liang, J. Kong and J. Gu, J. Hazard. Mater, 2018, 353, 166-172.

19. H. Gu, H. Zhang, C. Ma, X. Xu, Y. Wang, Z. Wang, R. Wei, H. Liu, C. Liu, Q. Shao, X. Mai and Z. Guo, Carbon, 2019, 142, 131-140.

20. H. Yang, P. Pi, Z. Q. Cai, X. Wen, X. Wang, J. Cheng and Z. Yang, Appl. Surf. Sci., 2010, 256, 4095-4102.

21. S. Peng, X. Yang, D. Tian and W. Deng, ACS Appl. Mater. Interfaces, 2014, 6, 15188-15197.

22. B. Qian and Z. Shen, Langmuir, 2005, 21, 9007-9009.

23. A. Zhang, M. Chen, C. Du, H. Guo, H. Bai, and Lei Li, ACS Appl. Mater. Interfaces, 2013, 5, 10201- 10206.

24. H. Lei, F. Wang, W. Li and G. Qiao, Sci. China. Mater, 2016, 59, 348-354.

25. R. N. Wenzel, Ind. Eng. Chem., 1936, 28, 988-994.

26. J. Li, D. Li, W. Li, H. She, H. Feng and D. Hu, Mater. Lett., 2016, 171, 228-231.

27. D. K. Owens and R. C. Wendt, J. Appl. Polym. Sci., 1969, 13, 1741-1747.

28. A. Checco, A. Rahman and C. T. Black, Adv. Mater, 2014, 26, 886-891.

29. S. A. Kulinich and M. Farzaneh, Appl. Surf. Sci., 2009, 255, 4056-4060.

30. W. Xu, R. Leeladhar, Y. T. Kong and C. H. Choi, Langmuir, 2013, 29, 6032-6041.

31. G. Mchale, S. Aqil, N. J. Shirtcliffe, M. I. Newton and H. Y. Erbil, Langmuir, 2005, 21, 11053-11060.

32. Z. Pan, S. Dash, J. A. Weibel and S. V. Garimella, Langmuir, 2013, 29, 15831-15841.

33. X. Zhang, S. Tan, N. Zhao, X. Guo, X. Zhang, Y. Zhang and J. Xu, Chemphyschem, 2006, 7, 2067-2070.

34. X. Zhang, Y. Zhao, S. Mu, C. Jiang, M. Song, Q. Fang, M. Xue, S. Qiu and B. Chen, ACS Appl. Mater. Interfaces., 2018, 10, 17301-17308.

35. L. Li, Z. Liu, Q. Zhang, C. Meng, T. Zhang and J. Zhai, J. Mater. Chem. A, 2015, 3, 1279-1286.

36. Y. Zhu, W. Xie, J. Li, T. Xing and J. Jin, J. Membr. Sci., 2015, 477, 131-138.

37. Z. Wang, X. Jiang, X. Cheng, C H. Lau and L. Shao, ACS Appl. Mater. Interfaces, 2015, 7, 9534-9545.

38. J. Li, R. Kang, X. Tang, H. She, Y. Yang and F. Zha, Nanoscale, 2016, 8, 7638-7645.

39. J. Li, Z. Zhao, D. Li, H. Tian, F. Zha, H. Feng and L. Guo, Nanoscale, 2017, 9, 13610-13617.

Publisher's Note Engineered Science Publisher remains neutral with regard to jurisdictional claims in published maps and institutional affiliations. 